\title{
CAN HEALTH CARE BENEFIT FROM MODELING AND SIMULATION METHODS IN THE SAME WAY AS BUSINESS AND MANUFACTURING HAS?
}

\author{
Jasna Kuljis \\ Ray J. Paul \\ Lampros K. Stergioulas \\ Department of Information Systems and Computing \\ Brunel University, West London \\ Middlesex, UB8 3PH, U.K.
}

\begin{abstract}
It has been increasingly recognized that the application of simulation methods can be instrumental in addressing the multi-faceted challenges health care is facing at present and more importantly in the future. But the application of these methods seems not to be as widespread as in other sectors, where such methods when used as part of their core operation, reap significant benefits. This paper examines the potential use of modeling and simulation in health care, drawing the parallels and marking the mismatches from the business and manufacturing world. Methods from the latter sectors will be reviewed with the intention to assess their potential usefulness to healthcare. To focus this discussion, we propose and discuss seven axes of differentiation: patient fear of death; medical practitioners (for example approach to healing, investigation by experimentation and finance); healthcare support staff; health care managers; political influence and control; 'society's view'; and utopia.
\end{abstract}

\section{INTRODUCTION}

The health care sector faces unprecedented levels of change, and its scale and complexity are also daunting. "Metrics of performance" have been introduced to guide or ease the process of change, but progress in one area (e.g. waiting times) is often at the expense of another (e.g. clinical priorities). The healthcare literature contains a large range of numerical and simulation techniques, but their application does not appear as widespread as in other sectors, which have long adopted such methods as part of their core operation, reaping significant benefits (Eldabi et al, 2007). A common criticism of the way such methods have been used in health care is that the approach often taken is tool-driven, starting from a "given" solution and trying to find a health care problem that fits to it ("a solution seeking a problem"), instead of having a real problem (which can be either well-defined or unknown/poorly defined) and seeking a modeling and simulation solution for it ("a problem seeking a solution"). It might well be that the way in which modeling and simulation methods are often used in industry requires adaptation for healthcare, because patients are not typical customers, mainly because they are more responsive and increasingly keen to exercise meaningful and informed choice. It is after all their lives that could be at stake!

This paper examines the potential use of modeling and simulation in health care, starting with a review of previous non-health care applications to assess their potential usefulness to healthcare. The challenges of bridging the socio-technical divide will also be discussed, focusing on how modeling and simulation might be used in such a context, to facilitate sociotechnical solutions, while embracing aspects of performance, efficiency and effectiveness. To focus this discussion, we propose and discuss seven axes of differentiation: patient fear of death; medical practitioners (for example approach to healing, investigation by experimentation and finance); healthcare support staff; health care managers; political influence and control; 'society's view'; and utopia.

\section{BUSINESS AND MANUFACTURING}

This study is the preliminary stage of an extensive literature review. This activity consists of a survey process, which includes academic and grey (industry and professional) literature, followed by analysis and classification through analogy, and aims to identify methods from the business and manufacturing sectors that may be applied to implement improvements in health care (a useful discussion on this potential can be found in (Young et al., 2004)). The hypothesis under investigation is that, despite the apparent complexity and uniqueness of health care and the inherent difficulties of making meaningful comparisons, sensible analogies with other types of systems can be made.

As a pilot, a small-scale literature review has been conducted, covering publications on industrial applications of simulation over the last three years. The Scopus citation database (http://www.scopus.com) was searched to identify academic and grey literature concerned with the use of numerical and simulation methods in industry. Scopus is arguably the largest citation database and indexes approximately 15,000 peer- 
reviewed journals from more than 4000 publishers (Elsevier, 2007). The search was conducted with the Boolean keyword combination "simulation AND industry" and was restricted to cover literature published from 2005 to 2007.

Table 1: Simulation techniques applied for various purposes in different industries

\begin{tabular}{|c|c|c|}
\hline Technique & $\begin{array}{l}\text { Industry } \\
\text { sector }\end{array}$ & Purpose of application \\
\hline \multirow[t]{3}{*}{$\begin{array}{l}\text { Discrete- } \\
\text { Event } \\
\text { Simulation }\end{array}$} & Iron \& Steel & $\begin{array}{l}\text { Improvement in production } \\
\text { process }^{\star} \text {, inventory } \\
\text { management, new product } \\
\text { development }\end{array}$ \\
\hline & Automobile & $\begin{array}{l}\text { Improvement in production } \\
\text { process }^{*}\end{array}$ \\
\hline & Construction & $\begin{array}{l}\text { Logistics and operations, } \\
\text { construction scheduling. }\end{array}$ \\
\hline \multirow[t]{3}{*}{$\begin{array}{l}\text { Continuous } \\
\text { simulations }\end{array}$} & Iron \& Steel & $\begin{array}{l}\text { Improvement in production } \\
\text { process*, new product } \\
\text { development }\end{array}$ \\
\hline & Pharmacology & $\begin{array}{l}\text { Improvement in production } \\
\text { process }^{\star} \text {, new product } \\
\text { development }\end{array}$ \\
\hline & $\begin{array}{l}\text { Process } \\
\text { industry }\end{array}$ & $\begin{array}{l}\text { Improvement in production } \\
\text { process }^{*}\end{array}$ \\
\hline \multirow[t]{3}{*}{$\begin{array}{l}\text { System } \\
\text { Dynamics }\end{array}$} & Construction & $\begin{array}{l}\text { Training, real-time planning, } \\
\text { resource allocation }\end{array}$ \\
\hline & Energy & Asset management \\
\hline & Automobile & Decision making \\
\hline \multirow[t]{3}{*}{$\begin{array}{l}\text { Monte- } \\
\text { Carlo } \\
\text { simulation }\end{array}$} & Construction & $\begin{array}{l}\text { Incentives and disincentive } \\
\text { based contracting, construction } \\
\text { scheduling, risk modeling }\end{array}$ \\
\hline & Energy & $\begin{array}{l}\text { Power trading, market place } \\
\text { simulation, competitive } \\
\text { strategy, expansion planning }\end{array}$ \\
\hline & Biotechnology & Growth projection \\
\hline \multirow{2}{*}{$\begin{array}{l}\text { Multi-agent } \\
\text { simulation }\end{array}$} & Construction & Supply chain simulation \\
\hline & Energy & $\begin{array}{l}\text { Emergency planning, energy } \\
\text { pricing, Power trading, market } \\
\text { place simulation, competitive } \\
\text { strategy, }\end{array}$ \\
\hline \multirow{3}{*}{$\begin{array}{l}\text { Virtual } \\
\text { reality/3-D } \\
\text { simulation }\end{array}$} & Iron \& Steel & Training, \\
\hline & Automobile & New product development \\
\hline & Construction & $\begin{array}{l}\text { Training, improve } \\
\text { communication and conveying } \\
\text { of concepts }\end{array}$ \\
\hline \multirow[t]{3}{*}{$\begin{array}{l}\text { Artificial } \\
\text { Intelligence }\end{array}$} & Automobile & $\begin{array}{l}\text { Improvement in production } \\
\text { process* }^{*}\end{array}$ \\
\hline & Construction & $\begin{array}{l}\text { Construction scheduling, risk } \\
\text { modeling }\end{array}$ \\
\hline & Energy & $\begin{array}{l}\text { Expansion planning, market } \\
\text { place simulation, power } \\
\text { trading, financial analysis }\end{array}$ \\
\hline
\end{tabular}

* Includes: Production lead-time reduction, dispatch/ loading bay scheduling, production process scheduling, reduction in machine changeover costs, cost reduction, etc.

The search returned around 600 abstracts. All these abstracts were read and 164 abstracts were found suitable for inclusion in the literature review. The abstracts were read with the aim to extract three specific information attributes, namely, the simulation technique that was used, the industry sector where simulation was applied and the purpose of applying simulation. A detailed description of the literature review methodology can be found in (RIGHT, 2007). Table 1 shows a subset of this categorization, covering the simulation and modeling techniques, industry sectors and purposes of simulation that were identified to be important in this initial phase of literature review. The selected abstracts were sourced from the following wide variety of journals

- Automation in Construction

- Automotive Engineer

- Chemical Engineer

- Computer-Aided Civil and Infrastructure Engineering

- Computers and Operations Research

- Construction Management and Economics

- Design Engineering

- Energy

- Energy and Fuels

- Energy Policy

- Engineering, Construction and Architectural Management

- Engineering Optimization

- European Journal of Operational Research

- Food and Bioproducts Processing

- IEEE Transactions on Evolutionary Computation

- IEEE Transactions on Industrial Electronics

- IEEE Transactions on Power Systems

- Information Systems

- International Journal of Biotechnology

- International Journal of Computer Integrated Manufacturing

- International Journal of Global Energy Issues

- International Journal of Management and Decision Making

- International Journal of Production Economics

- International Journal of Project Management

- International Journal of Services and Operations Management

- International Journal of Software Engineering and Knowledge Engineering

- Iron and Steel Technology

- Journal of Computing in Civil Engineering

- Journal of Materials Processing Technology

- Journal of Molecular Graphics and Modelling

- Journal of System Simulation

- Journal of Power Sources

- Naval Research Logistics

- New Electronics

- Nuclear Engineering International

- Oil and Gas Science and Technology

- Power System Technology

- Process Engineering

- Production Planning and Control

- Research Policy

- Simulation

- Simulation Modelling Practice and Theory 
- Transportation Research Part B: Methodological

- Transportation Research Part E: Logistics and Transportation Review

- Transportation Research Record

\section{PRELIMINARY RESULTS}

Based on impact and frequency of application, a relatively small number of simulation techniques were identified as important, mainly comprising of mainstream simulation methods as well as simulation algorithms based on Artificial Intelligence:

Discrete-event simulation has been used mainly for testing different strategies for increasing dispatch bay productivity, reducing transport costs by minimizing the waiting times for vehicles, job shop scheduling, logistics and operations in construction, and analysis of the construction inspection process. It is obvious that there are many potential uses of discrete-event simulation in health care areas, such as logistics, patient pathway design, reengineering, and management, scheduling and queue management, and reduction of waiting times.

Continuous simulation is used for dynamic thickness simulation in iron and steel industry, for determining the values of important equipment design parameters at the process development stage in pharmacology, for simulation-based comparison of production batch sizes in the process industries (those with continuous manufacturing processes), for the prediction of temperature profiles and hygienic design by means of continuous fluid dynamics (CFD) simulations in the food industry, etc. The applicability of this method to health care seems to be limited to physical/biological laboratory processes.

System dynamics (SD) has been used in the construction industry, for error and change management, for strategic and operational project management, for dynamic resource management; in the energy sector, to support development of asset management strategies for network utility companies; in the automobile industry, to make medium or long term decision related to supply chains. Potential applications to healthcare include resource and asset allocation and management, patient pathway design and management, strategic and operations management, and change management.

Monte Carlo simulation techniques have been used for knowledge-based scheduling analysis, for validation of simulation-based incentive and disincentives model in the construction industry, for assessing risks in infrastructural projects, for calculation of electricity options pricing models, for solving optimization problem related to expansion planning for electricity transmission systems, and for predicting the contribution of biotechnology industry in the future. Applications to health care may include risk analysis and management, incentivisation, and decision making/support under conditions of uncertainty (e.g. in commissioning, procurement, policy making, organizational change etc.).

In this pilot literature survey of modeling and simulation methods in industry, it has been found that agent-based simulation is also being used extensively in the energy industry (for example, oil and gas, electricity supply, etc.). This simulation technique is used for modeling optimal solution for power system restoration, for determining electricity prices based on customer demand, for agent-based computational economics, for studying the effects of various deregulated electricity market structures, for multi-agent based negotiation in electricity contract market, etc. In the construction industry, agent-based simulation has been used for modeling construction supply networks. Potential applications to health care may include management of demand and supply, health economics, and risk management.

In the construction industry, 3-D and virtual reality simulations are generally used for improving communication between people involved in construction and their clients. This is usually achieved through modeling virtual buildings in 3-D. In the automobile industry, virtual simulation tools are used for new product development. Potential applications to healthcare include the development of new services and pathway design reengineering, as well as any visual simulation application.

\section{APPLICABILITY OF SIMULATION IN HEALTH CARE}

The increasing pressures on the heavily resourceconstrained healthcare sector, accentuated by an ageing population and by the raised expectation thresholds of patient groups who have been encouraged to perceive themselves as the "centre" of the service, will continue to put the systems supporting clinical and managerial decision-making of care providers and their managers under increasing scrutiny (Littlejohns et al., 2003). In our context, there is a valid question of how to best address the challenges of bridging the socio-technical divide, first identified by pioneers such as Mumford (Mumford 1983; Mumford 2003). The need to incorporate human behavior in healthcare simulation models has also been highlighted (Brailsford et al., 2006; Brailsford 2002). To this end, health care will need to embrace aspects of both systemic and systematic modeling. We propose a systemic approach, which takes into account the key stakeholders' as well as the process perspectives (Lehaney and Paul, 1996; Connell 2001). Key ingredients of successful adoption of simulation techniques in health care include a method selection framework and the wide dissemination of good practice within the stakeholder communities (Eldabi and Young, 2007; Young 2005).

It is well known that the use of modeling and simulation is widespread in business and manufacturing, and essential the management of any type of organization. Recent studies suggest that the heath care is either inexperienced in such methods or prone to failure, and seemingly, accounts of unsuccessful experiences abound in the healthcare literature. In our pilot literature survey, we have identified potential uses of modeling 
and simulation to health care. But what is their real application potential for health care and what are the pluses and minuses of such methods for different applications? We would also like to examine why there are these differences between health care and other sectors.

\section{SEVEN AXES OF DIFFERENTIATION}

To discuss meaningfully the application potential of the identified simulation techniques in health care, we consider seven axes of differentiation in health care and examine how they impact on the applicability of such techniques. The axes, which were first introduced by Paul and Kuljis (2007), are:

- $\quad$ patient fear of death;

- medical practitioners, for example approach to healing, investigation by experimentation and finance;

- healthcare support staff;

- $\quad$ health care managers;

- political influence and control;

- 'society's view'; and

- utopia.

These axes span the whole range of health care provision; although no claim is made that this is the comprehensive set of such axes this provides an inclusive view of the health care distinctiveness. But so far, they seem to account for all the different health care stakeholders that audiences of Paul and Kuljis (2007) have come across.

Our conjecture is that the complexity of the health care domain, as manifested in the multitude of involved stakeholders and in these seven axes of differentiation from other sectors, is one of the main reasons for its relative sluggishness to adopt modeling and simulation methods.

The patients' fear of death introduces unpredictable pressures and often irrationality to the system. Medical practitioners are a diverse community, who can be highly opinionated, and often disagree on many clinical, organizational and other issues (for example: approach to healing, investigation by experimentation and finance).

Healthcare support-staff typically have a different view of a health care organization. On the other hand health care managers make decisions that influence all the levels of the organization and are often faced with complex situations where opposing forces need to be reconciled.

The health care sector is overly responsive and sensitive to political influence and control. Political intervention to health care is usually closely linked to the so-called 'society's view' of healthcare. Finally, society's aspiration for a health care Utopia ("an everhealthy society where nobody dies") shows no sign of subsiding.

We argue that the many different health care stakeholders, with their diverse interests and views, impose a number of unique pressures that are not encountered in other industry sectors.
Because of this, health care is often faced with tougher challenges; for instance on how to connect up different layers (governmental, organizational, service, procedural, physical) in modeling new services or changes to existing services, or of how to evaluate systemically the long-term impact of complex health care policies (e.g. patient choice, waiting times targets, private-public partnerships, etc.).

\section{CONCLUSIONS}

The findings of our pilot literature review have clearly shown that many methods from business and manufacturing are potentially applicable to health care. However, their practical application is not straightforward, mainly due to the diversity and unique attitudes of the human actors involved.

We argue that the identified seven axes of differentiation should inform the process of transferring modeling know-how and best practice to healthcare, and to be successful, any modeling and simulation application should take these seven axes into account and incorporate the needs of all health care stakeholders, as an integral part of the model.

\section{FUTURE?}

Although modeling and simulation methods have successfully been applied for years in business and manufacturing, their impact on health care seems to be problematic. We argue that the distinctiveness and singularities of health care affect quantitative modeling, and ignoring them makes the modeling useless, if not harmful.

A systemic approach, which takes into account the key stakeholders' as well as the process perspectives, would help to boost the usefulness and adoption of modeling and simulation to health care. Key ingredients of successful adoption of simulation techniques in health care may include a participatory approach to include the many health care stakeholders, a health-care-oriented method selection framework, and the wide dissemination of good practice within the stakeholder communities.

To be successful, any modeling and simulation application in health care should take the identified seven axes of differentiation into account and incorporate the needs of all health care stakeholders, as an integral part of the model.

\section{ACKNOWLEDGMENTS}

We would like to thank Dr Navonil Mustafee for his help with the methodology development and the implementation of the pilot literature review and Drs Mohsen Jahangirian and Tillal Eldabi for their valuable contribution to the development of the literature review methodology. This work is supported in part by the EPSRC, UK (RIGHT project, Grant No: EP/E019900/1; <http://wWw.right.org.uk>). 


\section{REFERENCES}

Brailsford S and B Schmidt. 2002. Towards incorporating human behaviour in models of health care systems: An approach using discrete event simulation. European Journal of Operational Research 150: 19-31.

Brailsford S.C., J. Sykes, and P.R. Harper. 2006. Incorporating human behavior in healthcare simulation models. In Proceedings of the 2006 Winter Simulation Conference, 466-472. Monterey, CA.

Connell, N.A.D. 2001. Evaluating Soft OR: some reflections on an "unsuccessful" implementation using an SSM-based approach. Journal of the Operational Research Society 52: 150 -160.

Eldabi, T. and T. Young. 2007. Towards a framework for healthcare simulation. To appear in Proceedings of the 2007 Winter Simulation Conference, ed. S.G. Henderson, B. Biller, M-H Hsieh, J. Shortle, J.D. Tew, and R.R. Barton, Washington DC, USA.

Eldabi, T., R.J. Paul, and T. Young. 2007. Simulation modelling in healthcare: reviewing legacies and investigating futures. Journal of the Operational Research Society 58: 262-270.

Elsevier. 2007. Scopus in Detail: Facts and Figures. Web resource <http://info.scopus.com/ detail/facts $>$ [accessed July 2, 2007].

Lehaney, B. and R.J. Paul. 1996. The use of soft systems methodology in the development of a simulation of outpatient services. Journal of the Operational Research Society 47: 864-870.

Littlejohns, P., J.C. Wyatt, and L. Garvican. 2003. Evaluating computerised health information systems: hard lessons still to be learnt. British Medical Journal 326: 860 - 863.

Mumford, E. 1983. Designing participatively: $A$ participative approach to computer systems design. Manchester Business School. UK.

Mumford, E. 2003. Re-designing Human Systems, Idea Group. Hershey, PA.

Paul, R.J. and J. Kuljis. 2007. Healthcare distinctiveness and singularities. Presented at the Fifth IMS International Conference on Quantitative Modelling in the Management of Healthcare, 2-4 April 2007. The Institute of Mathematics and its Applications.

RIGHT Consortium. 2007. Methodology for RIGHT Literature Review. Technical Report, Department of IS and Computing, Brunel University.

Young, T, 2005. An Agenda for Healthcare and Information Simulation, Health Care Management Science 8: 189-196.

Young, T., S. Brailsford, C. Connell, R. Davies, P. Harper and J.H. Klein. 2004. Using Industrial Processes to Improve Patient Care. British Medical Journal 328: 162-164.

\section{AUTHOR BIOGRAPHIES}

JASNA KULJIS is a professor in the Department of Information Systems and Computing at Brunel University, West London, UK. Her current research is in Human Computer Interfaces. She is mostly interested in the design of graphical user interfaces and in the development of new paradigms that would further enhance the usability of interactive computer systems. Professor Kuljis is the Director of the People and Interactivity Research Centre at Brunel University.

RAY J PAUL is an Emeritus Professor in the Department of Information Systems and Computing at Brunel University, and Visiting Professor in the Department of Information Systems at the London School of Economics. Ray taught Operational Research and Information Systems at LSE for 21 years, then joined Brunel for 12 years before retiring early on the grounds of permanent ill-health - he has Parkinsonism. Ray has over 400 refereed publications and 3 books. He is co-editor of the European Journal of Information Systems, which he co-founded in 1990 . He is one of the Editors of the Journal of Computing and Information Technology. Ray's research interests are in business modelling, particularly simulation, and information systems development. He has held over $£ 1.5 \mathrm{~m}$ in U.K. government grants in the last few years and collaborates with a vast array of international talent too numerous to mention, exemplified by his holding an Honorary Professorship in Community Medicine at Hong Kong University a few years ago. When not called upon to discombobulate, Ray writes his seven-book autobiography.

LAMPROS K STERGIOULAS is a Reader in the Department of Information Systems and Computing at Brunel University, West London, UK. His research interests include information engineering, medical and health informatics, human-centered information management, and biomedical data analysis. He holds numerous EU grants and is one of the co-investigators on RIGHT project funded by the EPSRC. 